\title{
Anterograde colonic stent placement via a cecostomy tube site
}

\author{
Lawrence M Gillman MD BSc (Med) BSc, Steven Latosinsky MD MSc FRCSC
}

\begin{abstract}
LM Gillman, S Latosinsky. Anterograde colonic stent placement via a cecostomy tube site. Can J Gastroenterol $2006 ; 20(6): 425-426$.

Colonic stents have been used as a method of relieving colonic obstruction since 1991. They are classically inserted in a retrograde fashion via the rectum and are deployed under a combination of endoscopic and fluoroscopic guidance. A unique case is presented where the colonic stent was passed in an anterograde fashion through a recently created cecostomy tube site as a method of palliation to relieve an obstructing hepatic flexure tumour.
\end{abstract}

Key Words: Cecostomy; Colonic neoplasms; Intestinal obstruction/radiography/surgery; Stents

T he use of expandable metal stents to relieve colonic obstruction was first reported in 1991 by Dohmoto (1). The stent is inserted in a retrograde fashion via the rectum and is deployed under a combination of endoscopic and fluoroscopic guidance. Velling et al (2) previously reported the placement of a colonic stent which was facilitated by a cecostomy tube. The guidewire was passed in an anterograde fashion through the cecostomy tube but the stent itself was inserted in the classic retrograde fashion via the rectum. To the best of our knowledge, the present paper represents the first report of this procedure being performed in an entirely anterograde fashion via a cecostomy tube site.

\section{CASE PRESENTATION}

An 80-year-old man with a history of class III angina and associated congestive heart failure was referred for investigation of anemia and a positive fecal occult blood test. During colonoscopy, he was found to have a circumferential invasive adenocarcinoma of the distal hepatic flexure. As part of his preoperative workup, he underwent a computed tomography scan which, in addition to demonstrating his colonic lesion, revealed a suspicious mass in his right groin. Shortly after his diagnosis, he presented to the emergency department with worsening abdominal pain, distension and obstipation for two days. Abdominal x-ray revealed a dilated right colon to the level of the hepatic flexure.

Because of his cardiac status, a cecostomy was performed in the operating room. A large Malecot tube (Teleflex Inc, Canada) was inserted into the cecum via a small right lower quadrant incision.

After a short course of observation in the surgical intensive care unit, the patient was transferred to the ward on postoperative day 2. His groin mass was biopsied and showed adenocarcinoma. Due to the presence of metastatic disease and his poor cardiac condition, even on maximal medical therapy, the focus of ongoing management was palliative and no further surgery was planned.

\section{Pose d'une endoprothèse dans le côlon par voie antérograde à partir d'une sonde de caecostomie}

\begin{abstract}
Les endoprothèses servent au soulagement de l'obstruction du côlon depuis 1991. La pose se fait généralement par voie rétrograde en passant par le rectum, et la mise en place est réalisée sous guidage endoscopique et fluoroscopique. Voici un premier cas de pose d'une endoprothèse dans le côlon par voie antérograde à partir d'une sonde de caecostomie pratiquée depuis peu à titre de traitement palliatif d'une tumeur obstructive, située à l'angle droit du côlon.
\end{abstract}

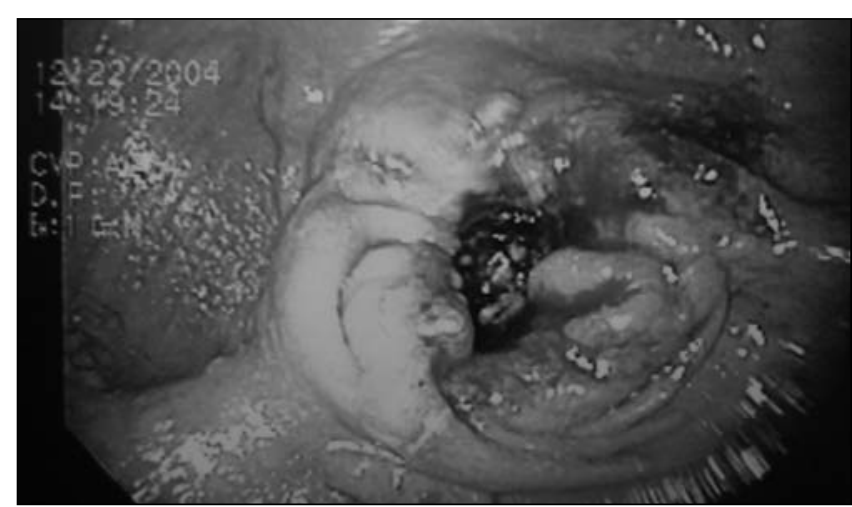

Figure 1) A view of the obstructing hepatic flexure lesion via a pediatric gastroscope placed in an anterograde fashion through the cecostomy site

The Malecot tube drained well into an ostomy bag, but it provided a challenge in terms of stoma care, which distressed the patient and was interfering with discharge planning. Four weeks postcecostomy tube insertion, the patient was brought to the fluoroscopy suite for placement of a colonic stent through the cecostomy site.

The Malecot tube was removed. An $11.3 \mathrm{~mm}$ PCF Q140L Olympus (Olympus Inc, USA) pediatric colonoscope was passed through the cecostomy tube site and the tumour was visualized (Figure 1). A thin band of contrast passed through the obstruction when infused via the gastroscope and viewed under fluoroscopy. The scope was used to pass a guidewire through the tumour under visualization with fluoroscopy. The scope was then removed and a $20 \mathrm{~mm} \times 90 \mathrm{~mm}$ uncovered Wallstent Enteral Endoprosthesis (Boston Scientific, USA) was passed directly through the cecostomy tube site over the

Department of Surgery, Faculty of Medicine, University of Manitoba, Winnipeg, Manitoba

Correspondence: Dr Lawrence Gillman, 260 Brodie Centre, 727 McDermot Avenue, Winnipeg, Manitoba R3E 3 P5.

Telephone 204-787-7581, fax 204-787-4063, e-mail SLatosinsky@exchange.hsc.mb.ca

Received for publication October 27, 2005. Accepted December 16, 2005 


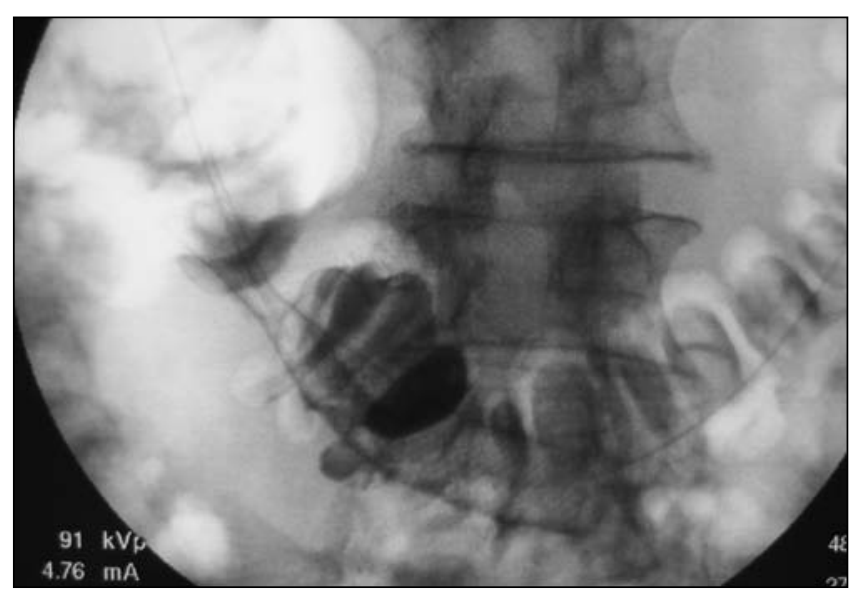

Figure 2) Fluoroscopic image of a $20 \mathrm{~mm} \times 90 \mathrm{~mm}$ uncovered Wallstent Enteral Endoprosthesis (Boston Scientific, USA) deployed across the obstructing tumour

guidewire. It was positioned across the lesion under fluoroscopic guidance and then deployed (Figure 2).

The patient began passing flatus and stool per rectum on postoperative day 2 . The output from the cecostomy site dramatically decreased and only required dressing changes twice a day. The patient continued to have regular bowel movements and was medically stable but remained in hospital for 14 days postprocedure at the request of physiotherapy and occupational therapy; he was then discharged home. The cecostomy site was left open and allowed to seal by secondary intention.

The patient returned to the emergency room several weeks later with an obstruction at the site of the stent. The cecostomy site was almost closed; however, in the fluoroscopy suite, a small catheter was inserted via this site and its position in the colonic lumen was confirmed. The stent appeared to be in good position and no evidence of migration was observed. The impacted stool was easily cleared with multiple litres of diatrizoate meglumine and the patient was discharged home the same day with an increase in his stool softeners. Subsequently the stent remained patent, and at follow-up, nearly six months later, the patient was still alive and under the care of the local palliative service.

\section{DISCUSSION}

Up to $30 \%$ of patients with colorectal cancer present with an acute large bowel obstruction (3). Traditionally, this was treated with an emergency laparotomy and diverting colostomy or a primary resection with end colostomy. A primary anastamosis was rarely performed because of the high risk of anastamotic

\section{REFERENCES}

1. Dohmoto M. New method - Endoscopic implantation of rectal stent in palliative treatment of malignant stenosis. Endosc Digest 1991;3:1507-12.

2. Velling TE, Hall LD, Brennan FJ. Colonic stent placement facilitated by percutaneous cecostomy and antegrade enema. Am J Roentgenol 2000;175:119-20.

3. Mauro MA, Koehler RE, Baron TH. Advances in gastrointestinal intervention: The treatment of gastroduodenal and colorectal obstructions with metallic stents. Radiology 2000;215:659-69.

4. Isbister WH, Prasad J. The management of left-sided large bowel obstruction: An audit. Aust NZ J Surg 1996;66:602-4.

5. Perrier G, Peillon C, Liberge N, Steinmetz L, Boyet L, Testart J. Cecostomy is a useful surgical procedure: Study of 113 colonic obstructions caused by cancer. Dis Colon Rectum 2000;43:50-4. complications. This acute surgery also carried a high rate of mortality, estimated to be between $6.5 \%$ and $13 \%(4,5)$. This is partly due to the poor premorbid condition of the cancer patient, who is typically older, malnourished and dehydrated. In addition, the colostomy stoma itself may be a major source of morbidity and decreased quality of life. It also necessitates a second surgery to restore intestinal continuity and, in fact, up to $25 \%$ of patients never have their stomas closed (6). In these cases, intestinal stenting offers an alternative to emergency surgery. It serves to decompress the obstruction, thus allowing time for preoperative investigations. If the tumour is deemed to be resectable, a bowel preparation can be administered and a single-stage procedure consisting of en bloc resection and primary anastamosis can be performed. In one case series, nine patients presenting with large bowel obstruction underwent colonic stenting as a bridge to surgery. All nine patients later underwent a single-stage procedure within two to 11 days. There were no deaths and no anastamotic leaks (7). In addition, a small case series involving four patients reported laparoscopic resection of a tumour following stent placement, thus suggesting yet another possible advantage of converting emergency surgery into a more elective procedure (8).

Alternatively, if the tumour is not deemed to be resectable, or the patient is not medically fit for surgery, the colonic stent can serve as a palliative procedure and an emergency colostomy with its potential morbidity and mortality is avoided (9). A review of the colonic stent literature published in the British Journal of Surgery in 2002 (10) revealed that successful palliation was achieved in $90 \%$ of the 336 patients who underwent palliative colonic stent placement for colorectal obstruction.

Most of the reports in the literature have been on left-sided obstructions. However, this technique has been more recently used for obstructions of the proximal colon as well (11).

Previous reported cases of stent placement for right-sided colonic obstruction involved the stent being passed in the classic retrograde fashion via the rectum (11). These cases can be quite challenging due to the length and tortuosity of the colon. While we considered using this technique, we were ultimately unable to do so because a long delivery system, capable of reaching the hepatic flexure, was not available at our institution. Thus, it was decided instead to proceed in an anterograde fashion via the cecostomy tube site.

Here we have presented a unique method for stenting right-sided lesions in an anterograde fashion through the use of a cecostomy tube site.

ACKNOWLEDGEMENTS: Dr Latosinsky was supported by the Rudy Falk Clinician Scientist Award.

6. Deans GT, Krukowski ZH, Irwin ST. Malignant obstructions of the left colon. Br J Surg 1994;81:1270-6.

7. Dauphine CE, Tan P, Beart RW, Vukasin P, Cohen H, Corman ML. Placement of self-expanding metal stents for acute malignant largebowel obstruction: A collective review. Ann Surg Oncol 2002;9:574-9.

8. Morino M, Bertello A, Garbarini A, Rozzio G, Repici A. Malignant colonic obstruction managed by endoscopic stent decompression followed by laparoscopic resections. Surg Endosc 2002;16:1483-7.

9. Bhardwaj R, Parker MC. Palliative therapy of colorectal carcinoma: Stent or surgery? Colorectal Dis 2003;5:518-21.

10. Khot UP, Lang AW, Murali K, Parker MC. Systematic review of the efficacy and safety of colorectal stents. Br J Surg 2002;89:1096-102.

11. Campbell KL, Hussey JK, Eremin O. Expandable metal stent application in obstructing carcinoma of the proximal colon: Report of a case. Dis Colon Rectum 1997;40:1391-3. 


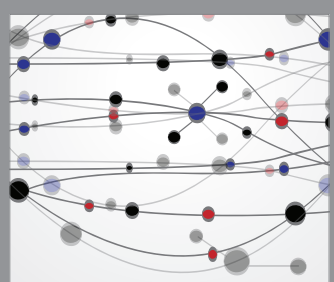

The Scientific World Journal
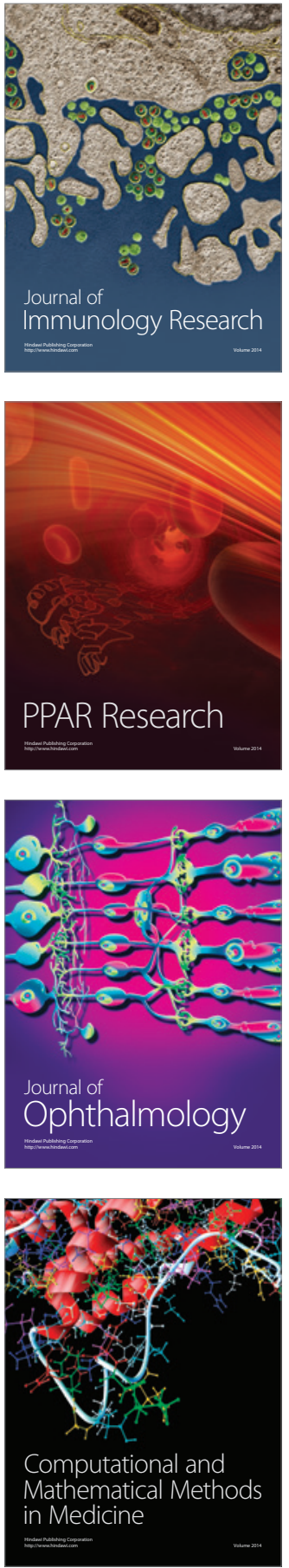

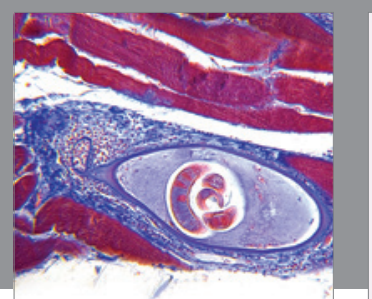

Gastroenterology Research and Practice

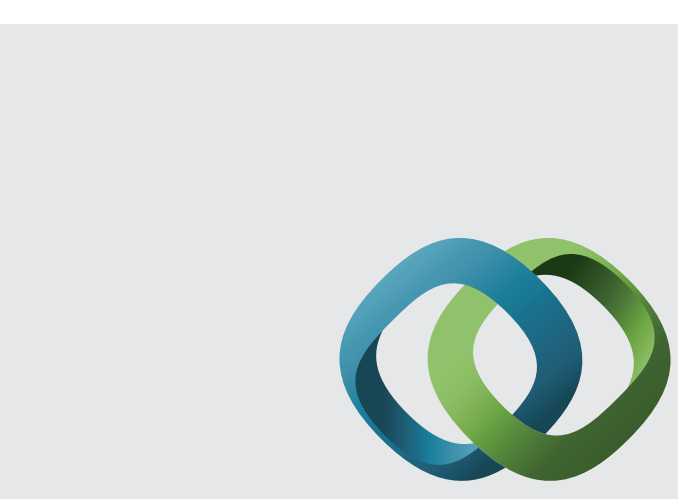

\section{Hindawi}

Submit your manuscripts at

http://www.hindawi.com
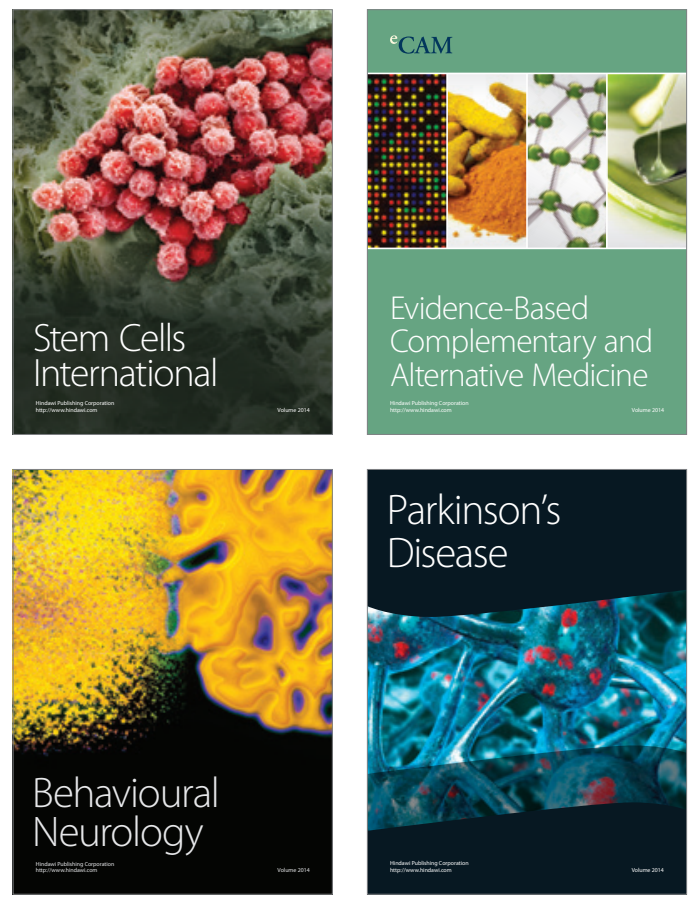
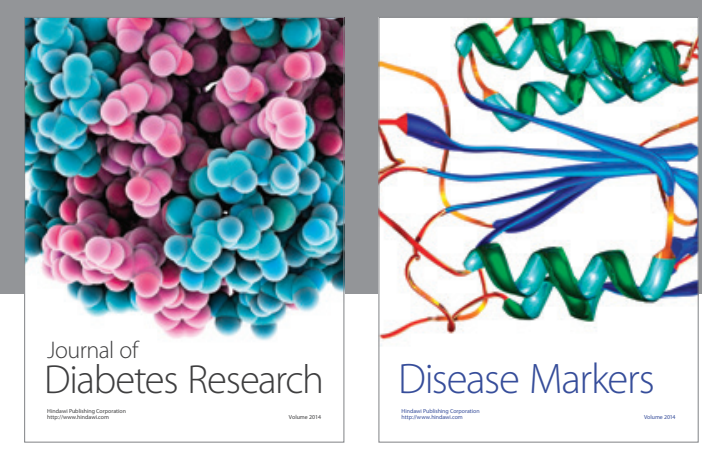

Disease Markers
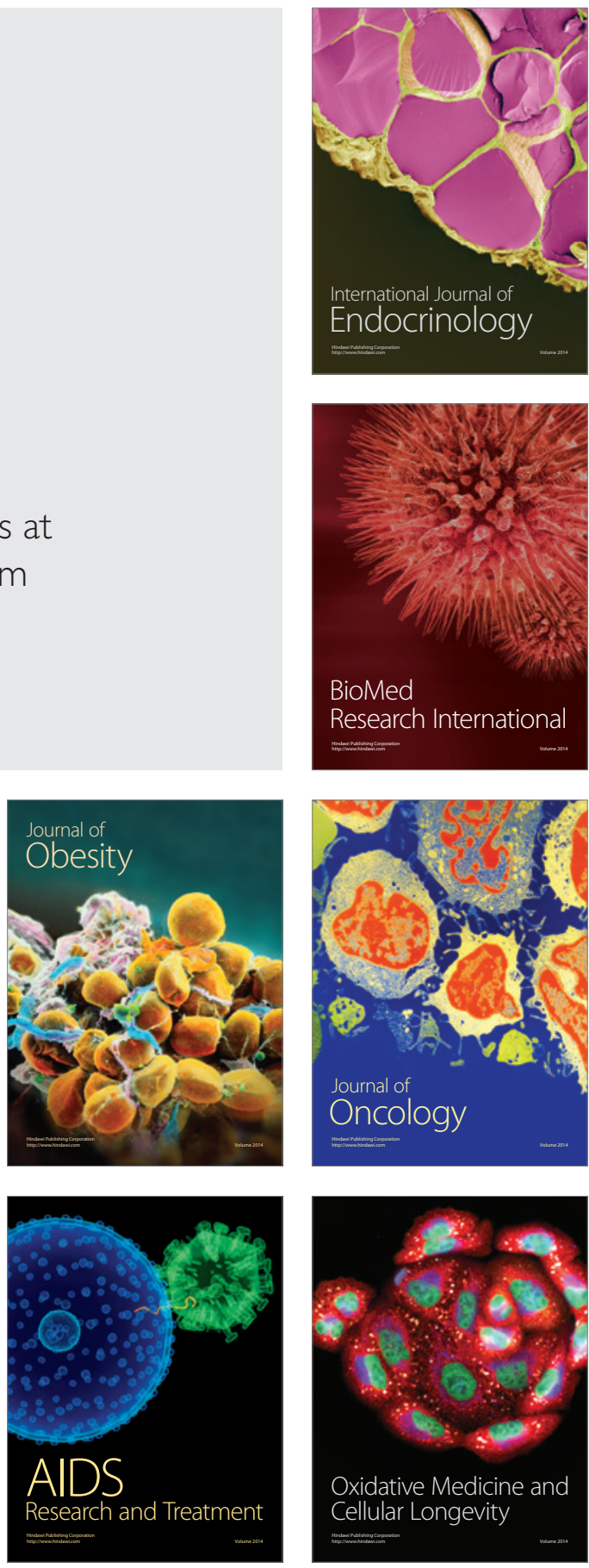